\title{
La canción en el rock argentino, Almendra, un comienzo
}

\author{
Elina Goldsack
}

[Universidad Nacional del Litoral]

Resumen El presente trabajo se ocupa de las canciones de un disco fundacional en la historia del rock en la argentina: Almendra. Grabado entre abril y septiembre de 1969 en los estudios T.N.T. y editado por RCA, Sony Music, el disco contiene nueve canciones caracterizadas por el eclecticismo poético y musical.

Considerando este disco como una bisagra de la canción popular argentina, nos proponemos indagar fundamentalmente en la relación textomúsica. Poniendo el foco en ese vínculo complejo donde se potencian el decir de la palabra y el decir de los sonidos.

¿Dónde radica la innovación en relación a este vínculo? ¿En particularidades métricas? ¿En formas que no responden al esquema estrofaestribillo? ¿En armonías o melodías que enfaticen estas particularidades? A partir del análisis musical focalizado en estos aspectos pretendemos encontrar algunas respuestas.

Esta investigación se encuentra enmarcada en el CAI+D 2016 "Cambios en innovaciones en la canción popular argentina a partir de los “60. Desafíos a las categorías vigentes” que se desarrolla en el Instituto Superior de Música de la Universidad Nacional del Litoral.
Summary This work deals with the songs of a foundational album in the history of rock in Argentina: Almendra. Recorded between April and September 1969 at T.N.T. studios and edited by RCA, Sony Music, the album contains nine songs characterized by poetic and musical eclecticism.

Considering this album as a hinge of the Argentine popular song, we intend to investigate fundamentally the text-music relationship, focusing on that complex link where the saying of the word and the saying of the sounds are enhanced. Where is the innovation in relation to this link? In metric particularities? In ways that do not respond to the verse-chorus scheme? In harmonies or melodies that emphasize these particularities? From musical analysis focused on these aspects, we try to find some answers. This research is framed in the CAI + D 2016 "Changes in innovations in Argentine popular song from the ' 60 . Challenges to the current categories" that takes place at the Instituto Superior de Música of the Universidad Nacional del Litoral. 


\title{
LA CANCIÓN ARgENTINA COMO OBJETO DE ESTUdio
}

\author{
¿Quién te enseñó la canción que cantabas?- preguntó Kuy-Kuyen. \\ Nadie me la enseñó-respondió Cucub. Es mi canción, \\ yo la imaginé. Allá, en la Comarca Aislada, cada uno tiene \\ su propia canción. La inventamos el mismo día en que nos reconocen \\ adultos para que nos acompañe durante toda nuestra vida.
}

$\sim$ Liliana Bodoc, 2008

Las canciones y la música cruzan como hilos de una tela la historia de la Saga de los Confines de Liliana Bodoc, acompañan a sus personajes en despedidas, funerales, alegrías y tristezas. El relato de la escritora nos invita a escuchar interiormente esas canciones que aparecen en la narración y nos propone imaginar la música que las acompańa. Quizá no todos podamos crear nuestras canciones como el personaje de la novela de Bodoc, pero sí podríamos armar un mapa de canciones que nos recuerde momentos especiales o etapas de la propia vida. La canción de cuna, la canción de la infancia, la que conocimos a través de una amiga, la que musicalizó un encuentro inolvidable, la que podríamos escuchar mil veces, la que acompaña nuestra tristeza, la que nos identifica políticamente, la que nos da mucha alegría y ganas de bailar, la que nos identifica generacionalmente entre otras tantas que podríamos describir. Así lo describe Pablo Semán en el prólogo del libro Las mil y una vida de las canciones:

Estamos hechos de canciones porque cada canción, cada uso de una canción configura un signo de un lenguaje emocional que se acumula en la historia de los sujetos y las generaciones que forman parte de una dinámica de capas geológicas. (Semán, 2019: 19)

Las canciones nos acompañan como fotos sonoras y congelan o reviven emociones a partir de una mezcla de música, letra e interpretación que las valida. Dice Pujol citando a Heloísa Valente:

si, como afirma la musicóloga brasileña Heloísa Valente, los signos musicales, y en particular la canción, pueden funcionar como cápsulas de memoria -su poder evocativo aumenta en proporción a la distancia temporal entre el evento ocurrido y el tiempo presente- es razonable suponer que la eficacia de 
esas «cápsulas» depende no sólo de los intérpretes que las tocaron con la varita mágica de sus voces sino también de la calidad de sus materiales y de las maneras con la que éstos fueron ensamblados. (Pujol, 20ı: I4)

Emilio del Guercio, músico, cantante integrante del grupo Almendra, en su programa "Cómo Hice» (2009-2013), que presenta el primer archivo audiovisual de la canción popular argentina, describe la importancia de la canción en el arte popular y en la vida de las personas:

Las canciones definen como ninguna otra manifestación del arte popular, un espacio simbólico, el que guarda las claves genéticas de la cultura. Ellas llegan a nuestros corazones y por algún motivo indescifrable, algunas, se quedan para siempre. ¿De dónde vienen las canciones?, estamos en la búsqueda. Queremos saber cómo se produce el paso desde la soledad del creador en su casa hacia ese otro momento mágico, cuando la gente toma la canción como bien de uso espiritual para acompañar los días de su vida, y la convierte en cultura. (Del Guercio, 2009)

Cada episodio del programa es un reportaje a un compositor/a o cantautor/a en relación al proceso creativo de una canción específica que se contrasta con distinas opiniones de músicos y público. Testimonios, recuerdos, emociones se conjugan buscando la forma de comprender la trascendencia de las canciones elegidas. Indagar en las claves genéticas de la cultura que contienen las canciones, como describe Del Guercio, es encontrar los rasgos musicales que las caracterizan, los móviles emocionales que le dieron origen, el contexto donde fueron creadas, el paisaje que las contiene y la permanencia en la cultura de un grupo etario, pueblo o país. Es aquí donde nos encontramos como grupo de trabajo con la intención de indagar en las particularidades de la canción argentina, en el gran desafío de describirla y de encontrar su genealogía. Ante este gran objetivo, focalizamos en un momento histórico que fue testigo de grandes cambios e innovaciones como la década del sesenta y en discos claves en la historia de la cultura popular argentina de esa época.

De cualquier manera, la mirada hacia atrás resultó ineludible. Es así, como a través del trabajo de Sergio Pujol en su libro Canciones Argentinas, pudimos recorrer un panorama del sonido anterior a esta época. Este libro, que sustenta su organización en los soportes tecnológicos que posibilitaron la expansión masiva de las canciones, comienza en el centenario y termina en el bicente- 
nario como marco histórico, contiene cinco capítulos en relación a los soportes mencionados: "Canciones en la victrola (I9IO-I934)», "Lo que cantaba la radio (I935-1956)», "Los años del Wincofón (1957-I970)», "Piezas de un álbum (I97I-I987)» y «Canciones a la vista (I988-20I0)». En un recorrido de I40 canciones el autor nos ofrece un panorama analizable desde muchas perspectivas: las duplas creativas, las improntas fundamentales de las versiones, los vínculos con películas en algunos casos, los usos del lenguaje, las temáticas vinculadas a las épocas y a los géneros. Es en éste aspecto que nos interesa focalizar nuestro trabajo, ya que resulta muy evidente la variedad de géneros que aparecen bajo la denominación "canción argentina». De lo observado en los tres primeros capítulos que llegan hasta I970, podemos ver la preeminecia del tango desde I9Io a I960 aproximadamente, el crecimiento del folklore en el segundo período, alguna canción española, la canción testimonial, la canción melódica y los boleros en el tercer capítulo junto con la aparición del rock argentino en 1968. Es ineludible observar también desde la perspectiva de género la lista de canciones, el lugar de mayor participación femenina se encuentra en la interpretación, mientras que la autoría aparece en 1920 con Rosita Melo y 1930 con Mercedes Simone, y no aparecen creadoras hasta 1960 con la llegada de Eladia Blázquez y María Elena Walsh. De las I40 canciones, solo seis pertenecen a compositoras. A las cuatro mencionadas se agregan Azucena Maizani y Gilda. Cada eslabón de esta cadena creativa vista en el tiempo tiene diferentes cambios e innovaciones tanto en lo musical como en lo poético, pero la década del sesenta se vislumbra como un período de grandes búsquedas y creaciones. La canción infantil con María Walsh, las renovaciones en el tango con Astor Piazzolla y Eladia Blázquez, el Nuevo Cancionero con su aporte en el folklore, la canción con rasgos de Comedia Musical (un movimiento liderado por Nacha Guevara, Jorge de la Vega, Mariquena Monti y Jorge Schussheim, entre otros) y el nacimiento del rock argentino con una gran particularidad en sus distintos representantes conforman un período de mucha creatividad. Nuevos poetas, nuevas formas de decir se vincularon con nuevas búsquedas, formas y prácticas musicales.

Surge una pregunta ineludible: ¡faltan canciones en este libro? Sí, muchas, pero lo que resulta evidente, también, es que las que están son parte fundamental de nuestra cultura y nuestra identidad. Este panorama de canciones nos acerca a la dimensión de lo que significó la aparición del disco Almendra en nuestra realidad cultural. 


\section{LA BúSQUeda de un ANÁlisis MUSical QUE INCLUYa EL TEXTO}

¿Cómo estudiar las canciones? ¿Cómo analizarlas? A partir del disco que nos ocupa, voy a exponer planteos teóricos acordes a este trabajo y algunas propuestas de análisis.

Creadas por una persona o por una sociedad compositiva, en un contexto, en un tiempo y lugar específicos, las canciones contienen tramas complejas de sentido que implican diversas posibilidades de interpretación y recepción. Emprender su estudio implica una convergencia de posibles miradas, como lo explica Juan Pablo González:

El hecho de que la canción popular permita distintas formas de abordaje, es un claro índice de la presencia de diferentes textos en ella. De este modo, si para un crítico literario la canción es un poema, para un musicólogo será un plan armónico y formal, para un ingeniero será una mezcla sonora, para un sociólogo será una agenda de acción social, para un crítico cultural será la manifestación de un cuerpo valórico e ideológico, y para un semiólogo será todas estas cosas juntas y ninguna en particular. (González, 20I3: IOO)

La visión del musicólogo, nos propone la idea de grupos de trabajo o de discusión y reflexión que aporten a una comprensión más abierta y caleidoscópica del impacto social y creativo que propone una canción.

Siguiendo con la propuesta de Juan Pablo González y en relación con la mirada musicológica es que el autor propone un proceso de «ensanche» del concepto de lo musical y de la forma que se ha construido su análisis intertextual desde diferentes puntos de escucha. Es así que plantea la canción concebida como suceso, al ser tocada o cantada, como objeto cuando se convierte en una partitura (a partir de la transcripción), o en una grabación analizable auditivamente desde la performance (en grabación o en vivo) y como proceso textual, cuando la canción se compone, se arregla, se interpreta, se graba, se mezcla, se masteriza, se reversiona, se habla de ella o se analiza. Cerrando la explicación del objeto al proceso, plantea:

De este modo, la canción se va conformando a partir de distintas prácticas sociales generadora de textos, que son producidos, usados y cargados de sentido por distintas personas,en diferentes momentos de su puesta en marcha. (González, 2013: I09) 
Es a partir de las diferentes recepciones, usos y resignificaciones que las canciones se convierten en trashumantes, en palabras de Pablo Seman, y en algunos casos son resignificadas por sus propios autores (Seman: 2019).

Podríamos citar como ejemplo dos canciones del disco Almendra: el caso de Ana no duerme, grabada en 1968 y versionada por el mismo Spinetta en 1998 con su grupo Los Socios del Desierto, es en este caso el mismo cantautor quien lleva la canción a otros intérpretes y a otras formas de comunicación artística. Por el riff utilizado, el patrón rítmico, el formato tímbrico, la distorsión de la guitarra, la forma de cantar, el tempo (el más rápido del disco), podríamos decir que es la canción más rockera del disco, siendo la version posterior una especie de confirmación en el tiempo, con cambios que intensifican el sentido de la versión orginal, llevándola a un tipo de rock más duro, con un riff diferente, un poco más lento y contundente y con una forma de cantar más hablada, no tan melódica. También lo hace con Laura va, en la versión para MTV con Carlos Franzetti, con un arreglo mas al estilo Beatles que el original de Rodolfo Alchourrón, que tiene tímbricas más contrapuestas y un sentido más tanguero, no sólo por la inclusión del bandoneón sino también por quien lo toca (Rodolfo Mederos) y por la forma de cantar del propio Spinetta.

Volviendo al proceso textual que propone González y en relación al «ensanche» del análisis es que queremos incluir en el mismo el vínculo de la letra con la música, no sólo desde el planteo compositivo, sino también desde el arreglo y la interpretación.

Simon Frith, en su libro Ritos de la interpretación, le dedica un capítulo a este vínculo y en relación a como escuchamos propone tres aspectos importantes:

[...] al escuchar las letras de las canciones pop, lo que escuchamos son tres cosas a la vez: las palabras, que parecen darles a las canciones una fuente de significación semántica autónoma; la retórica, palabras usadas de manera especial, de manera musical, una forma que llama la atención sobre aspectos y problemas discursivos; y las voces, palabras habladas o cantadas con tonos humanos que son en sí mismos «significativos» signo de una persona y de una personalidad. (Frith, 20I4: 284)

Es interesante escuchar Figuración a partir de estos planteos de Frith. En esta canción la parte "b" del estribillo "si vas a perder tu amor // alguien te ha dicho ya // aunque no eres real // vas a perder tu amor» aparece por primera vez cantada, con melodía. Cuando aparece por segunda vez, tiene la primera parte («a») con letra distinta y la segunda parte («b») es recitada por un coro mascu- 
lino. Este cambio tímbrico y expresivo sobre el texto produce sensaciones totalmente distintas, la versión cantanda sigue el discurso de pedido de imaginación a un personaje sin nombre y le anticipa lo que le va a pasar («vas a perder tu amor»), mientras que la aparición del coro recitado produce una sensación de «comentario intimidante» sobre el relato, ocupando las mismas palabras.

ANÁLISIS DE «FIgURACIón »

Tempo: negra 62

Total de compases: 53

\begin{tabular}{|c|c|c|c|c|}
\hline Forma & Intro & Estrofa 1- & Estrofa 2 & Estribillo 1 \\
\hline & INST. & $\begin{array}{l}\text { Figúrate que pierdes } \\
\text { la cabeza } \\
\text { sales a la calle } \\
\text { sin embargo el } \\
\text { mundo } \\
\text { sigue bajo el sol, } \\
\text { todo bajo el sol } \\
\text { debajo del sol }\end{array}$ & $\begin{array}{l}\text { Figúrate que no eres } \\
\text { más un hombre } \\
\text { sales a la calle } \\
\text { sin embargo hay } \\
\text { árboles } \\
\text { como hubo ayer, } \\
\text { calles como ayer } \\
\text { luces como ayer. }\end{array}$ & $\begin{array}{l}\text { En la plaza todo te } \\
\text { parece igual } \\
\text { tú ya no eres hombre } \\
\text { pero llorarás } \\
\text { si vas a perder tu } \\
\text { amor } \\
\text { alguien te ha dicho } \\
\text { ya } \\
\text { aunque no eres real } \\
\text { vas a perder tu amor. }\end{array}$ \\
\hline $\begin{array}{l}\text { METRO- } \\
\text { Cant. de } \\
\text { compases }\end{array}$ & $\begin{array}{l}3 C(2 / 4-4 / 4 \\
-4 / 4)\end{array}$ & $8 C$. & 7C. & $8 \mathrm{C}$. \\
\hline
\end{tabular}

\begin{tabular}{|c|c|c|c|c|c|}
\hline Inter & Estrofa 3 & Estribillo 2 & Inter & Estrofa 4 & Coda \\
\hline & $\begin{array}{l}\text { Figúrate que pierdes } \\
\text { la cabeza } \\
\text { y aunque no lo creas } \\
\text { se te va la voz } \\
\text { como se fue tu piel } \\
\text { nada te queda ya, } \\
\text { sólo la realidad. }\end{array}$ & $\begin{array}{l}\text { La realidad es } \\
\text { caminar igual } \\
\text { tú ya no eres hombre } \\
\text { pero llorarás } \\
\text { Si vas a perder tu } \\
\text { amor } \\
\text { alguien te ha dicho ya } \\
\text { aunque no eres real } \\
\text { vas a perder tu amor. } \\
\text { (coro hablado) }\end{array}$ & & $\begin{array}{l}\text { Figúrate que has } \\
\text { vuelto a ser el } \\
\text { mismo } \\
\text { nada te contenta } \\
\text { a partir del alba } \\
\text { te verás caer, ya sin } \\
\text { figurar, } \\
\text { te verás caer. } \\
\text { (RALL.) }\end{array}$ & Rall. \\
\hline $\begin{array}{l}2 \mathrm{C}(2 / 4 \\
4 / 4)\end{array}$ & $8 \mathrm{C}$ & $7 \mathrm{C}$ & $\begin{array}{l}2 C \\
(2 / 4 \\
4 / 4)\end{array}$ & $7 \mathrm{C}$ & 3c. \\
\hline
\end{tabular}

Figura I Análisis de la vinculación entre texto, forma y métrica en la canción Figuración. (letra y música: Luis Alberto Spinetta). 
Simon Frith se refiere también a la uniformidad de las canciones pop respondiendo a una práctica compositiva concesiva con el gusto de «jueces» de la industria musical, conviertiéndose en algunos casos también en «fórmulas del amor», ya que esta temática es una constante en estas canciones. Refiréndose al tratamiento de estas las letras sugiere diferentes miradas:

Alternativamente, puede hacerse un contraste entre la versión estandarizada del amor y otra cosa, algo más real, compleja e individual. Letras de «molde», frases «sentimentales» $\mathrm{y}$ «banales» se oponen rutinariamente a las letras «realistas», a canciones que tratan del mundo real y de emociones vividas. (Frith, 20I4: 288)

Es a partir de este tipo de descripción de la canción de amor donde Muchacha ojos de papel puede aparecer como contraste a la canción de "fórmula romántica» descripta por Frith, ubicándose en el lugar de las canciones que hablan de «emociones vividas» con el agregado de un alto contenido poético. Es muy interesante aquí también la autocrítica que realiza Spinetta sobre la letra de su canción veinte años más tarde en un especie de «manifiesto filosófico» (en sus propias palabras) y en el programa "Cómo hice» junto a Emilio del Guercio, donde plantea que esa letra está escrita por un machista que quiere «ser dueño" de esa chica y que ahora no lo representa. Esto también estaría hablando de los cambios en las costumbres sociales que reflejan las canciones de amor (Frith, 20I4: 288). También es interesante ver las diferentes interpretaciones de la canción, cuando Del Guercio expone lo que esta canción representa para él.

¿Cómo se vinculan la música y la palabra? ¿Cómo se transforma una letra de amor en una melodía de amor? ¿En base a qué decisiones? En este caso, Spinetta elige la balada para decir esta letra, con tempo lento, tocada con una guitarra acústica, con aire de canción folk, coros y una forma de cantar intimista.

Estas elecciones musicales vinculadas a la letra nos confirman la relación en la que nos queremos focalizar. ¿Cómo resolver la correspondencia texto literario-música pero desde la música, desde la perspectiva de parámetros y aspectos musicales concretos con las letras? Es a partir de esta pregunta que planteamos una Lista de vinculos entre texto literario y música, que puedan ser aplicados a la performance, en vivo o en grabaciones, y a las partituras o transcripciones. 


\section{Lista De VÍNCULOS ENTRE TEXTO LITERARIO Y MÚSICA, UNA PROPUESTA}

Temáticas - significados - género - patrón rítmico

$\sim$ Texto literario - estructura formal

$\sim$ Texto literario - ritmo: tempos elegidos, tipo de tratamiento del texto, uso de acentuaciones, silábico o melismático. Rimas, conteo de sílabas en relación a compases o motivos o células rítmicas. Palabras utilizadas con efectos rítmicos

$\sim$ Texto literario - melodía-armonía. Giros melódicos, progresiones armónicas o cambios armónicos que enfaticen el sentido del texto o constituyan una unidad con el mismo que lo caracterice o identifique

$\sim$ Texto literario - temáticas - textura - timbres - arreglo

$\sim$ Texto literario -modos de cantar en relación a lo expresivo y a las colocacion o timbres de voz

\section{ANÁlisis DE «PLEgARIA PARA UN NIÑo DORMIDO »}

Aplicando especialmente las categorías 2 y 3 en el disco Almendra, observamos en Plegaria para un niño dormido y en Figuración que la forma estrofa - estrofa - estribillo se modifica en la repetición.

Tempo: Negra 72

\begin{tabular}{|l|l|l|l|l|}
\hline Forma & \multicolumn{1}{|l}{ Intro } & \multicolumn{1}{l}{ Estrofa 1- } & \multicolumn{1}{l}{ Estrofa 2 } \\
\hline INST. & $\begin{array}{l}\text { Plegaria para un niño } \\
\text { dormido } \\
\text { quizás tenga flores } \\
\text { en su ombligo } \\
\text { y además en sus } \\
\text { dedos que se } \\
\text { vuelven pan } \\
\text { barcos de papel sin } \\
\text { altamar }\end{array}$ & $\begin{array}{l}\text { Plegaria para el } \\
\text { sueño del niño } \\
\text { donde el mundo es } \\
\text { un chocolatín. } \\
\text { Adonde van } \\
\text { mil niños dormidos } \\
\text { que no están } \\
\text { entre bicicletas de } \\
\text { cristal }\end{array}$ & $\begin{array}{l}\text { Se ríe el niño } \\
\text { dormido } \\
\text { quizás se sienta } \\
\text { gorrión esta vez } \\
\text { jugueteando inquieto } \\
\text { en los jardines de } \\
\text { un lugar } \\
\text { que jamás despierto } \\
\text { encontrará }\end{array}$ \\
\hline $\begin{array}{l}\text { METRO- } \\
\text { Cant. de } \\
\text { compases }\end{array}$ & 4/4- 5C & 9C. & 9C. & $\begin{array}{l}\text { 9C (cambio de } \\
\text { compás a 2/4 en } \\
\text { el compás seis) }\end{array}$ \\
\hline
\end{tabular}




\begin{tabular}{|c|c|c|c|c|c|}
\hline Estrofa 3 & Estribillo 2 & Puente & Estrofa 4 & Estribillo 3 & Coda \\
\hline $\begin{array}{l}\text { Que nadie, } \\
\text { nadie, despierte } \\
\text { al niño } \\
\text { déjenlo que } \\
\text { siga soñando } \\
\text { felicidad } \\
\text { destruyendo } \\
\text { trapos de lustrar } \\
\text { alejándose de } \\
\text { todo el mal (la } \\
\text { maldad) }\end{array}$ & $\begin{array}{l}\text { Se ríe el niño } \\
\text { dormido } \\
\text { quizás se sienta } \\
\text { gorrión esta vez } \\
\text { jugueteando } \\
\text { inquieto en los } \\
\text { jardines de un } \\
\text { lugar } \\
\text { que jamás } \\
\text { despierto } \\
\text { encontrará }\end{array}$ & & $\begin{array}{l}\text { Plegaria para un } \\
\text { niño dormido } \\
\text { quizás tenga } \\
\text { flores en su } \\
\text { ombligo } \\
\text { y además en sus } \\
\text { dedos que se } \\
\text { vuelven pan } \\
\text { barcos de papel } \\
\text { sin altamar }\end{array}$ & $\begin{array}{l}\text { Se ríe el niño } \\
\text { dormido } \\
\text { quizás se sienta } \\
\text { gorrión esta vez } \\
\text { jugueteando } \\
\text { inquieto en los } \\
\text { jardines de un } \\
\text { lugar } \\
\text { que jamás } \\
\text { despierto } \\
\text { encontrará. }\end{array}$ & \\
\hline $9 \mathrm{C}$. & $\begin{array}{l}9 \mathrm{C} \text { (cambio de } \\
\text { compás a } 2 / 4 \text { en } \\
\text { el compás seis) }\end{array}$ & $\begin{array}{l}2 \mathrm{C} \text { (uno } \\
\text { por elisión } \\
\text { con } \\
\text { estribillo) }\end{array}$ & & $\begin{array}{l}\text { 9C (cambio de } \\
\text { compás a } 2 / 4 \text { en } \\
\text { el compás seis) }\end{array}$ & $4 \mathrm{c}$ \\
\hline
\end{tabular}

Figura $2 \sim$ Análisis de la vinculación entre texto, forma y métrica en la canción Plegaria para un niño dormido (letra y música: Luis Alberto Spinetta).

Algunos estribillos tienen modificadas sus letras en las repeticiones, (Color Humano, A estos hombres tristes, Figuración). Asimismo, las letras conducen a irregularidades en el aspecto métrico, cambios de compás.

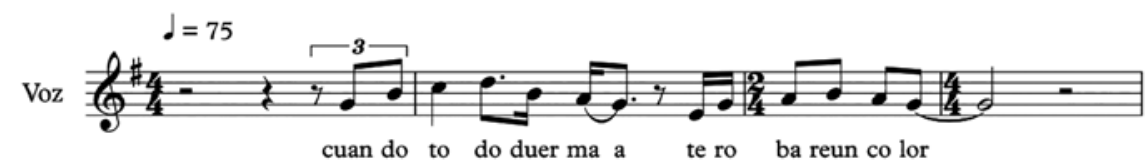

Figura $3 \sim$ Transcripción $^{1}$ del fragmento final de estribillo de Muchacha ojos de papel (letra y música: Luis Alberto Spinetta).

Voz

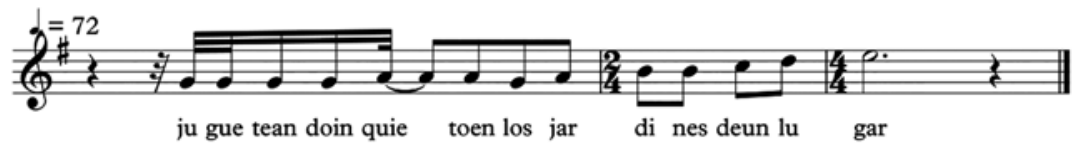

Figura $4 \sim$ Transcripción de un fragmento del estribillo de Plegaria para un niño dormido (letra y música: Luis Alberto Spinetta).

1 Todas las transcripciones del presente artículo fueron realizadas por la autora. 
Por otro lado, también observamos que las letras conducen a estrofas y estribillos irregulares en la cantidad de compases como vimos en la estrofa de Figuración. En el caso de Laura va, se aplican las tres últimas categorías propuestas (puntos 3, 4 y 5 ).

Como sugiere Sergio Pujol, esta canción formaría parte de una de las lecciones que Almendra aprendió de los Beatles en relación a la producción de sonoridades diferentes para cada canción (Pujol, 20I0: 224). Comienza con la voz sola, con un motivo melódico ascendente por grado conjunto de la tercera a la quinta del acorde cantando Laura va, se mantiene y se modifica algunas veces cuando jugando con las palabras y describiendo otro estado del personaje, lo cambia a "Laura ve». Este motivo se apoya sobre el acorde tónica de Re mayor al empezar y cambia al tercer grado (Fa\#menor) cuando dice "Laura ve». Otro aspecto sorprendente, en relación a lo formal y melódico armónico, es el final de la canción. Si bien la estructura responde a la forma estrofa - estrofa - estribillo, presenta una coda con letra, donde cuenta el final de la historia de la canción y modula por ataque directo a Do mayor. Dice Pujol en relación a la forma de cantar de Spinetta, «La misma voz que en el mismo LP busca el límite con Ana no duerme, en Laura Va evita todo énfasis.» (Pujol, 20Io).

La tímbrica y textura elegida para acompañar la historia es muy original y diferente. Comienza sin introducción, se escucha la voz y unas placas que responden con la misma melodía, después van apareciendo las cuerdas y agregándose los vientos de madera y una sutil guitarra eléctrica en la segunda estrofa, sobre el estribillo se escucha el refuerzo de los graves, se agrega un triángulo y hay un cambio a doce octavos. Aparece el arpa y se vuelve a escuchar ahora la voz con "Laura ve», en la segunda estrofa el bandoneón contesta a la aparición de la voz, desaparece en el estribillo que sostiene la misma sonoridad que la primera vez y vuelve a aparecer para la coda final.

Retomando diferentes planteos analíticos sobre la canción, es importante el trabajo realizado por María Inés Velázquez y Laura Otero en el libro Canciones bajo la lupa. Las autoras plantean el vínculo directo entre la célula con la palabra, y el motivo con el verso en la poesía (Velázquez y Otero, 20I4: I22). Tomando Fermín como ejemplo, podemos observar este vínculo analizando la primer estrofa. Ella consta de cuatro compases en el compás de cuatro tiempos de pie binario en la tonalidad de La mayor. Tres versos y tres motivos melódicos la constituyen. El primero («Las manos de Fermín») con tres acordes que los estructuran (I- IIIe-VI), el segundo («giran y él también») con dos (II y III) y el último («gira y da más vueltas») resolviendo con II-V-I. 


\section{FERMÍN}

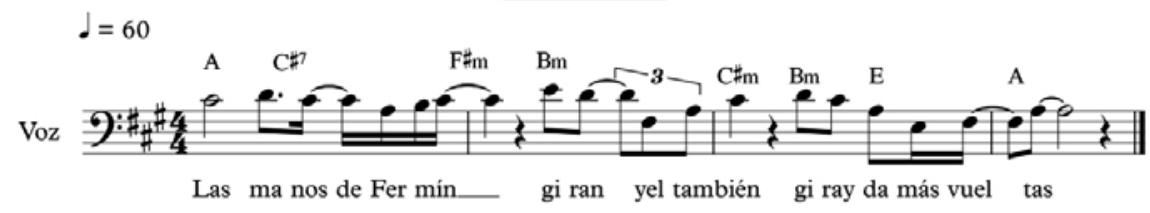

Figura $5 \sim$ Transcripción de un fragmento de Fermín (Letra y música: Luis Alberto Spinetta).

En relación al protagonista de esta canción, Julián Delgado lo describe de la siguiente manera:

Fermín, el protagonista de la primera canción del lado B del primer LP, era un personaje conocido en las calles del Bajo Belgrano. Un joven con problemas mentales que los vecinos solían tratar con simpatía, aunque a veces los más chicos se divirtieran gritándole o jugándole bromas tontas. [...] Con total inocencia, Fermín pone en cuestión los criterios que definen lo que es raro y lo que no. Es, en ese sentido, comparable con Ana, Laura o cualquier otro personaje del ábum. (Delgado, 20I7:II3 - II4)

Como señala Delgado, si bien no es un niño, la asociación con lo infantil aparece de muchas maneras en la canción y es en el final donde la cita a Mambrú propone esta relación: «Fermín se fue a la vida, no sé cuándo vendrá». Es aquí donde la melodía y la armonía se vinculan con el texto enfatizando su sentido, el «no sé cuándo vendrá» que en el original termina en el acorde de tónica, sorprende en esta versión, con un acorde de IV grado menor con novena, generando una sensación de final abierto, raro, que se va diluyendo con armónica y palmas (Punto 4 de la Lista).

\section{Música, TeXto, dibujos}

Existe otra relación aparte de la que venimos estudiando, y es la que propone el grupo Almendra en relación al emblemático payaso de la tapa y sus símbolos vinculantes. Mara Favoretto lo describe y lo interpreta: 
El payaso triste, vestido de rosa, con una sopapa en la cabeza que intenta extraer algo de su cerebro, con una nariz colorada como si tuviera frío, un frío probablemente provocado por el hielo de la ciudad, era un dibujo del propio Luis Alberto Spinetta. Ante esta imágen portadora de tal angustia, la palabra "Almendra» en su remera parecía traer un poco de energía dulzona a su tristeza. (Favoretto, 2017: 79)

Es a partir de esta imagen que se organizan las canciones del disco en tres grupos. Cada canción es acompañada de un símbolo que tiene que ver con el payaso de la tapa, cuatro canciones con la lágrima, tres con la sopapa y dos con el ojo. Exponemos tres cuadros que analizan clasificaciones generales que sirven de idea sonora del disco y que intentan observar si esas características tienen relación con la organización planteada.

En relación a las descripciones, hemos optado por utilizar el término «aire» para identificar aspectos sutiles vinculados a géneros o subgéneros en el marco de la estructura de la canción. Por otro lado, en cuanto a la forma, hemos designado como regular las estructuras que responden al esquema estrofa-estrofaestribillo y su repetición y como irregular a las que no responden a este formato.

Temas que canta el hombre de la tapa desmayado en el vacio

\begin{tabular}{|c|c|c|c|c|c|c|}
\hline $\begin{array}{l}\text { Canciones } \\
\text { Extensión }\end{array}$ & $\begin{array}{l}\text { Género o } \\
\text { subgénero }\end{array}$ & Timbres & Tonalidad & $\begin{array}{l}\text { Metro. } \\
\text { Tempo. }\end{array}$ & Forma & $\begin{array}{l}\text { Temáticas. } \\
\text { Significados }\end{array}$ \\
\hline $\begin{array}{l}\text { Color } \\
\text { Humano } \\
\text { Edelmiro } \\
\text { Molinari } \\
\text { 09:10 }\end{array}$ & $\begin{array}{l}\text { Canción } \\
\text { con aire } \\
\text { de blues }\end{array}$ & $\begin{array}{l}\text {-Voz: } \\
\text { Spinetta } \\
\text {-Guitarra } \\
\text { eléctrica } \\
\text {-Guitarra } \\
\text { acústica } \\
\text {-Bajo } \\
\text { Batería } \\
\text { pandereta }\end{array}$ & si menor & $\begin{array}{l}\text { Negra: } 65 \\
3 / 4 \\
4 / 4\end{array}$ & $\begin{array}{l}\text { Irregular } \\
\text { Incluye } \\
\text { improvisación }\end{array}$ & $\begin{array}{l}\text { Fantástico, } \\
\text { reflexivo }\end{array}$ \\
\hline $\begin{array}{l}\text { A estos } \\
\text { hombres } \\
\text { tristes. } \\
\text { (L.A.S.) } \\
06: 10\end{array}$ & Canción & $\begin{array}{l}\text { Voz. } \\
\text { Spinetta } \\
\text { Guitarra } \\
\text { eléctrica } \\
\text { Bajo } \\
\text { Batería } \\
\text { triángulo }\end{array}$ & do menor & $\begin{array}{l}\text { Negra: } 80 \\
4 / 4 \\
(6(8+2 / 8) \\
4 / 4-12 / 8- \\
5 / 8-2 / 4\end{array}$ & $\begin{array}{l}\text { Irregular } \\
\text { Improvisación } \\
\text { sobre el final }\end{array}$ & $\begin{array}{l}\text { Fantástico, } \\
\text { reflexivo, } \\
\text { existencialista }\end{array}$ \\
\hline
\end{tabular}


Temas que están en el brillo de la lágrima de mil años que llora el hombre de la tapa

\begin{tabular}{|c|c|c|c|c|c|c|}
\hline Canciones & $\begin{array}{l}\text { Género } \\
\text { Sub- } \\
\text { género }\end{array}$ & Timbres & Tonalidad & $\begin{array}{l}\text { Metro. } \\
\text { Tempo }\end{array}$ & Forma & $\begin{array}{l}\text { Temáticas. } \\
\text { Significados }\end{array}$ \\
\hline $\begin{array}{l}\text { Muchacha } \\
\text { (L.A.S.) } \\
\text { 03:07 }\end{array}$ & Balada & $\begin{array}{l}\text { Voz- } \\
\text { Spinetta } \\
\text { Voces- } \\
\text { grupo } \\
\text { Guitarra } \\
\text { acústica }\end{array}$ & Sol mayor & $\begin{array}{l}\text { Negra: } 75 \\
4 / 4-2 / 4\end{array}$ & Regular & $\begin{array}{l}\text { Canción } \\
\text { de amor. } \\
\text { Personaje sin } \\
\text { nombre }\end{array}$ \\
\hline $\begin{array}{l}\text { Figuración } \\
\text { (L.A.S.) } \\
\text { 03:32 }\end{array}$ & Canción & $\begin{array}{l}\text { Voz. } \\
\text { Spinetta } \\
\text { Coro } \\
\text { hablado } \\
\text { masculino } \\
\text { Guitarra } \\
\text { Flauta } \\
\text { dulce } \\
\text { Bajo } \\
\text { Batería }\end{array}$ & Do mayor & $\begin{array}{l}\text { Negra: } 62 \\
2 / 4 \\
4 / 4\end{array}$ & Irregular & $\begin{array}{l}\text { Fantástico, } \\
\text { existencialista }\end{array}$ \\
\hline $\begin{array}{l}\text { Plegaria } \\
\text { para } \\
\text { un niño } \\
\text { dormido } \\
\text { (L.A.S.) } \\
04: 03\end{array}$ & $\begin{array}{l}\text { Balada, } \\
\text { canción } \\
\text { de cuna }\end{array}$ & $\begin{array}{l}\text { Voz. } \\
\text { Spinetta } \\
\text { Coros } \\
\text { Guitarra } \\
\text { acústica } \\
\text { Guitarra } \\
\text { eléctrica } \\
\text { Piano } \\
\text { Bajo } \\
\text { cascabeles }\end{array}$ & Mi menor & $\begin{array}{l}\text { Negra:72 } \\
4 / 4 \\
2 / 4\end{array}$ & Irregular & $\begin{array}{l}\text { Canción de } \\
\text { cuna con } \\
\text { sentido social. }\end{array}$ \\
\hline $\begin{array}{l}\text { Que el } \\
\text { viento } \\
\text { borró tus } \\
\text { manos. } \\
\text { E.Del } \\
\text { Guercio } \\
02: 38\end{array}$ & $\begin{array}{l}\text { Canción } \\
\text { con aires } \\
\text { jazzeros. }\end{array}$ & $\begin{array}{l}\text { Voz. } \\
\text { Emilio Del } \\
\text { Guercio } \\
\text { Voces. } \\
\text { Flauta } \\
\text { dulce } \\
\text { Guitarra } \\
\text { eléctrica } \\
\text { Bajo } \\
\text { batería }\end{array}$ & Do menor & $\begin{array}{l}\text { Negra: } \\
105 \\
2 / 4-4 / 4 \\
12 / 8\end{array}$ & $\begin{array}{l}\text { Regular } \\
\text { (introducción } \\
\text { particular) }\end{array}$ & $\begin{array}{l}\text { Fantástico. } \\
\text { Personaje sin } \\
\text { nombre. }\end{array}$ \\
\hline
\end{tabular}


Temas que le cantan los hombres a esa lágrima del hombre de la tapa, atados a sus destinos

\begin{tabular}{|c|c|c|c|c|c|c|}
\hline Canciones & $\begin{array}{l}\text { Género } \\
\text { subgénero }\end{array}$ & Timbres & Tonalidad & $\begin{array}{l}\text { Metro. } \\
\text { Tempo. }\end{array}$ & Forma & $\begin{array}{l}\text { Temáticas } \\
\text { Significados }\end{array}$ \\
\hline $\begin{array}{l}\begin{array}{l}\text { Ana no } \\
\text { duerme }\end{array} \\
\text { (L.A.S.) } \\
02: 47\end{array}$ & Rock & $\begin{array}{l}\text { Voz: } \\
\text { Spinetta } \\
\text { coros } \\
\text { Guitarra } \\
\text { eléctrica } \\
\text { Guitarra } \\
\text { Órgano } \\
\text { Bajo } \\
\text { batería }\end{array}$ & Mi menor & $\begin{array}{l}\text { Negra: } \\
150 \\
4 / 4 \\
4 / 2 \\
12 / 8 \\
9 / 8\end{array}$ & Irregular & $\begin{array}{l}\text { Personaje. } \\
\text { Historia } \\
\text { fantástica }\end{array}$ \\
\hline $\begin{array}{l}\text { Fermín } \\
\text { (L.A.S.) } \\
03: 20\end{array}$ & Canción & $\begin{array}{l}\text { Voz- Emilio } \\
\text { del Guercio } \\
\text { Voces- } \\
\text { todos } \\
\text { Guitarra } \\
\text { eléctrica } \\
\text { guitarra } \\
\text { teclado } \\
\text { batería }\end{array}$ & La mayor & $\begin{array}{l}\text { Negra:68 } \\
4 / 4\end{array}$ & $\begin{array}{l}\text { Regular } \\
\text { (coda con } \\
\text { cita) }\end{array}$ & $\begin{array}{l}\text { Personaje. } \\
\text { Historia } \\
\text { fantástica }\end{array}$ \\
\hline $\begin{array}{l}\text { Laura va } \\
\text { (L.A.S.) } \\
02: 58\end{array}$ & $\begin{array}{l}\text { "Aire" de } \\
\text { tango }\end{array}$ & $\begin{array}{l}\text { Voz. } \\
\text { Spinetta } \\
\text { Celesta. } \\
\text { Cuerdas. } \\
\text { Vientos. } \\
\text { Guitarra } \\
\text { eléctrica. } \\
\text { bajo. Arpa. } \\
\text { bandoneón. }\end{array}$ & $\begin{array}{l}\text { Comienza } \\
\text { en Re } \\
\text { Termina } \\
\text { en Do. }\end{array}$ & $\begin{array}{l}\text { Negra:54 } \\
2 / 4\end{array}$ & $\begin{array}{l}\text { Regular } \\
\text { (coda } \\
\text { especial) }\end{array}$ & $\begin{array}{l}\text { Personaje. } \\
\text { Historia } \\
\text { fantástica. }\end{array}$ \\
\hline
\end{tabular}

Figura $6 \sim$ Posibles vinculaciones entre parámetros musicales y las temáticas planteadas en el disco Almendra.

Al observar estos datos podemos inferir varias cuestiones. En primer lugar, es interesante ver la variedad de sub-géneros que subyacen en lo que sería uno de los primeros discos de rock en la Argentina. El otro es el referido a la tímbrica, ya que si bien el grupo presenta una estructura instrumental y vocal, se agregan instrumentos y detalles a lo largo de todo el disco.

En relación a las tonalidades, existe variedad en la elección, solo se repiten Do menor y Mi menor, generando diferentes sonoridades. Las melodías presentan ámbitos extendidos, junto con giros modales y recursos tonales inusuales que después irán constituyendo el sello característico de Spinetta. Las estructuras formales y la métrica presentan continuos cambios que sorprenden en cada tema. 
Por último, analizando la relación con la propuesta del grupo, pareciera que la agrupación de los temas estaría vinculada a las temáticas. Siendo el primer grupo («Temas que canta el hombre de la tapa desmayado en el vacío») los que plantearían temáticas existencialistas y en este caso sí coincidirían algunas características musicales. Son los dos temas más largos del disco e incluyen improvisaciones, en el caso de Color Humano, Spinetta cuenta que les gustaba mucho para improvisar:

Cuando en los shows tocábamos Color humano, un gran tema de Edelmiro, para nosotros era una fiesta porque ahí podíamos improvisar, aunque algunos no entendieran nada. Igual no lo podíamos hacer tan largo porque si tocábamos ese tema muy improvisado después nos teníamos que ir. Los shows duraban sólo veinticinco minutos. (Diez, 20I6: 177)

Siguiendo con la clasificación, en «Temas que están en el brillo de la lágrima de mil años que llora el hombre de la tapa», están las canciones de amor y la de personajes sin nombre propio. Por último en «Temas que le cantan los hombres a esa lágrima del hombre de la tapa, atados a sus destinos», están las canciones referidas a los personajes con nombre propio e historias fantásticas.

\section{A MOdo DE CONCLUSIón}

Quiero terminar este trabajo compartiendo el texto del volante escrito a máquina que repartieron los integrantes de Almendra antes de la presentación del disco el is de enero de I970:

A lo largo de seis meses de intenso trabajo, de proposición total hacia lo que es nuestro, hemos comprendido que lo que en un momento puede llegar a trascender deja de ser exclusivamente propiedad del autor y se transforma en algo legítimamente de todos. Por eso el is de enero es una fecha importante tanto para nosotros como para ustedes. Es la salida de nuestro primer long play. Es nuestra salida hacia ustedes. (volante escrito a máquina y fotocopiado, distribuido por Buenos Aires)

Resulta revelador observar a la distancia que esa ilusión de trascendencia manifestada por el grupo tuvo eco en la sociedad argentina, que esas canciones 
consolidaron el inicio del rock en castellano, y que forman parte de la vida de muchas personas y generaciones hasta la actualidad.

En relación a la Lista de vínculos entre texto literario y música que presentamos, en este caso fue ejemplicada con el disco de Almendra, pero el grupo de investigación la viene aplicando sobre otros discos elegidos para este proyecto. Este es el caso de La Coronación del Folklore y Canciones para mirar de María Elena Walsh. Esto nos plantea diversos desafíos, ya que los géneros presentan particularidades específicas en relacion a esta connivencia. El folklore tiene un vínculo muy significativo con la danza que resulta determinante en las relaciones del texto literario y la música, y la canción infantil de María Elena Walsh parte de la creación de una poeta que compone y canta sus canciones. Nos encontramos en la tarea de desarrollar y mejorar la aplicación a las diferentes propuestas.

Estas "cápsulas de memoria», fotos sonoras o cápsulas de emociones que son las canciones, siguen proponiéndonos desafíos para su estudio. La propuesta del grupo Almendra de relacionar las canciones con las imágenes quizá anticipó ese vínculo tan presente en la actualidad y quizá también represente un campo de investigación de futuro desarrollo.

\section{Discografía}

ALMENDRA (1969). Almendra [CD-ROM]. Buenos Aires: RCA, Sony Music.

\section{ReCURSOS ELECTRónicos}

DEL Guercio, Emilio (productor). (2010). Como Hice. Ciudad Autónoma de Buenos Aires: Canal Encuentro. Recuperado de: https://www.youtube.com/ watch? $\mathrm{v}=27 \mathrm{mgyOZwjTQ}$

\section{Bibliografía}

Berti, Eduardo (2014). Spinetta. Crónica e iluminaciones. Ciudad Autónoma de Buenos Aires: Grupo Editorial Planeta

Delgado, Julián (2017). Tu tiempo es hoy. Una historia de Almendra. Ciudad Autónoma de Buenos Aires: Eterna Cadencia Editora

Dente, Miguel Ángel (2014). Tícher de luz. Una guía spinettiana. (3ed.). Ciudad Autónoma de Buenos Aires: Ediciones Disconario 
Díaz, Claudio (2005). Libro de viajes y extravíos: un recorrido por el rock argentino. Córdoba: Narvaja editor

Diez, Juan Carlos (2013). Martropía. Conversaciones con Spinetta. Ciudad Autónoma de Buenos Aires: Aguilar, Altea, Taurus, Alfaguara. S.A.

Duarte Valente, Heloísa (2000). "Os giros (do mundo) do disco na voz cancao". Opus 7. Disponible en http://www.anppom.com.br/revista/index.php/ opus/article/view/95/77 [Consultado 20 de abril de 2016]

Favoretto, Mara (2017). Luis Alberto Spinetta: mito y mitología. Ciudad Autónoma de Buenos Aires: Gourmet Musical Ediciones

Frith, Simon (2014). Ritos de la interpretación. Sobre el valor de la música popular. Ciudad Autónoma de Buenos Aires: Paidós.

Gilbert, Abel y Liut Martín (compiladores). (2019). Las mil y una vida de las canciones. Ciudad Autónoma de Buenos Aires: Gourmet musical

González, Juan Pablo (2013). Pensar la música desde América Latina. Ciudad Autónoma de Buenos Aires: Gourmet Musical Ediciones

Pujol, Sergio (2002). La década rebelde. Los años 60 en la Argentina. Ciudad Autónoma de Buenos Aires: Emecé

Pujol, Sergio (2010). Canciones argentinas (1910-2010). Ciudad Autónoma de Buenos Aires: Emecé

otero, LAURA Y VELAZQUeZ MARÍA INÉs (2014). Canciones bajo la lupa: un acercamiento metodológico para el análisis de poesía y música en la canción popular. Ciudad Autónoma de Buenos Aires: Barry Editorial.

\section{Registro bibliográfico}

ELINA GolDSACK: «La canción en el rock argentino, Almendra, un comienzo", en Revista del Instituto Superior de Música, número 17, Instituto Superior de Música, Santa Fe, UNL, República Argentina, 2020, pp. 25-42.

\section{Descriptores / Describers}

Canción · rock argentino $\cdot$ análisis 